\title{
Assemblage Theory and Town Foundation in Medieval England
}

\author{
Ben Jervis
}

\begin{abstract}
It is proposed that our understanding of medieval town foundation is limited by a failure to appreciate that 'town' is a relational category. It is argued that urban character emerges from social relations, with some sets of social relationship revealing urbanity and others not, as places develop along distinctive, but related, trajectories. This argument is developed through the application of assemblage theory to the development of towns in thirteenth-century southern England. The outcome is a proposal that, by focusing on the social relations through which towns are revealed as a distinctive category of place, we can better comprehend why and how towns mattered in medieval society and develop a greater understanding of the relationship of urbanization to other social processes such as commercialization and associated changes in the countryside.
\end{abstract}

\section{Introduction}

Assemblage theory (after Deleuze \& Guattari 1987; see also De Landa 2006) offers a means of thinking through archaeological data which forces us to explore how evidence finds meaning in relation to other fragments of knowledge about the past. Here it is proposed that thinking through assemblage theory, which, along with associated 'relational' approaches, has increasing currency in both archaeology (e.g. Fowler 2013; Harris 2014; Hodder 2012; Jervis 2014; Jones 2012) and human geography (Allen 2011; Dewsbury 2000; Dewsbury et al. 2002; McFarlane 2011), a radically different approach to the study of the medieval town can be taken (see Astill 1985; 2009; Dyer 2003, for general reviews of previous approaches). If we view the town as relational (that is, formed through the performance of social relationships), then it stands to reason that it emerges through some relationships and not others. Therefore, it is through these relations that a place is defined as urban and that the process of urbanism had relevance to medieval people. By implication, it might be argued that the town does not reveal itself through all sets of relations, suggesting that some elements of medieval society might transcend the urban/rural divide imposed through modern analysis.

This approach is used here to move away from seeking to define the town, a task which, as discussed below, is fraught with difficulty, and towards exploring the forms which medieval urbanism takes. In so doing, the value of assemblage theory to both medieval archaeology and settlement archaeology more generally, in shifting the focus of analysis from seeing places as simply urban to reflecting upon the processes which make them so, is demonstrated (see also Christopherson 2015). A problem with defining towns is that they take different forms and perform different roles. Attempts to define urban archaeological signatures have often resulted in frustration, highlighting patterns of similarity as well as dissimilarity between town and country, suggesting that fresh perspectives might be required (see, for example, Egan 2005; Pearson 2005). Through a consideration of the nature of categorization processes the first part of this paper proposes that categories of town emerged as people related to places and communities, meaning that different understandings of urbanism might exist simultaneously. Taking this as a starting-point, the remainder of the paper uses archaeological evidence

Cambridge Archaeological Journal 26:3, 381-395 $\quad$ C 2016 McDonald Institute for Archaeological Research. This is an Open Access article, distributed under the terms of the Creative Commons Attribution licence (http:/ / creativecommons.org/licenses/by/4.0/), which permits unrestricted re-use, distribution, and reproduction in any medium, provided the original work is properly cited.

doi:10.1017/S0959774316000159 Received 30 Mar 2015; Accepted 14 Feb 2016; Revised 11 Dec 2015 
from the Weald of Sussex (UK) to propose that, rather than being a characteristic of a place, urbanism is an emergent quality of assemblages of actants (that is, the people, things and materials which participate in social practice) linked through performances of everyday life. This discussion leads to a call to move from an emphasis on site-specific interpretation to a multi-scalar consideration of the processes through which different forms of urbanism come to be revealed through the analysis of past practice, finding parallels with recent considerations of urban processes in Scandinavia in particular (Ashby et al. 2015; Christopherson 2015; Sindbaek 2007).

\section{Defining towns: unpacking an analytical black-box}

We all think we know what the word town means. A picture of a relatively small but densely settled place, a commercial centre with some administrative function, probably springs to mind. Yet the definition of the word continues to be debated in medieval studies. 'Town' stands for more than a place; it is an analytical 'black-box' (that is a concept which crystallizes past action and circulates as a referential starting-point; see Latour 2010, 160), standing for a tradition of historical and archaeological study (see Fowler 2013). The term circulates as a reference to a particular type of settlement which does not appear to be primarily rural in character. Debates about what exactly we mean by town are not new, being as old as the medieval settlements themselves. Masschaele $(1997,79-83)$ discusses how tax assessment forced the urban character of places to be considered, as towns and villages were taxed differently. Places such as Andover (Hampshire), whose community probably saw themselves as urban, having a guild merchant and borough charter, for example, were taxed at the rural rate. This highlights how places might simultaneously have been perceived as urban and rural. Assessments made for specific purposes categorized places as towns, with these categorizations being enacted through administrative practice. As these practices were repeated, through the enacting of this assessment, so 'town', as a reference to a particular process of categorization circulated, forming a reference against which towns as a category of place were understood. Importantly, this medieval categorization of places shows that settlements without borough charters (that is, granted certain freedoms seen to be fundamental to urban life) could be perceived of as towns.

Through historical documents, therefore, we have inherited an understanding that some places were towns and that some were not; but this under- standing is partial, directed by categorizations made for specific purposes and passed on to us through an incomplete historical record. Furthermore, inconsistencies between sources make it difficult to develop a firm definition of what a town is. Attempts to overcome this by creating a check-list of urban characteristics (Biddle 1976; Reynolds 1977) have been unsuccessful, as only the largest towns fulfil all of the criteria and certain characteristics might be considered as more important than others. A pragmatic and commonly used definition is that towns are places which have an economy that is largely dependent upon activities other than agriculture (Dyer 2002, 7). Whilst this is satisfactory, in that it allows the distinction between urban and rural places to remain fuzzy, its vagueness limits its utility. Dyer $(2002,7)$ cautions against critiquing the contrast between town and country too deeply, as it is an important analytical distinction, which can be considered relevant within the medieval mind.

Whilst it is true that the category of town was meaningful in the medieval period, Masschaele's (1997) work shows how 'town' was interpreted differently depending upon the context of categorization. Historians and archaeologists have specific reasons for wanting to categorize places as urban or rural; they seek, for example, to know how town life differed from village life, or how agricultural production related to the marketing of produce. The debate has been undertaken in relation to the circulating reference of the town-we know this category is real, but what were these places for? Beresford saw towns as an instrument of lordship, founded to market agricultural surplus and generate income; they were 'specialized centres of making and dealing' (Beresford 1967, 55-6). Medieval society is typically seen as being agrarian and, therefore, towns have been set in opposition to rural settlements, as an anomalous feature in an agricultural economy. Following Hilton (1992) in particular, scholarship shifted towards seeing urban and rural as united within an economic system, with towns being necessary for the disposal of surplus and the manufacture and exchange of other commodities. In order to function, towns require a degree of freedom or liberty, creating the town, or borough, as a specific category of place (Hilton 1992, 10-14). Hilton points to similarities in the social organization of town and country: tensions between ruling and peasant classes and the organization of economic activity around the household unit in particular. He uses this to demonstrate that towns were not anomalous within medieval society; however, we might also ask whether these similarities relate to the ambiguity over the classification of places discussed 
previously. Perhaps towns are a useful category when discussing economic networks, but in relation to other elements of life do not emerge as a distinctive category. This past analysis has created a reference which has circulated over the intervening centuries, leading us to attempt to work backwards to try to place a settlement within or outside this category (see also Christopherson 2015, 112). I argue that this approach has resulted in an analytical seizure. 'Town' as a category emerged and was 'black-boxed' through circulation in the assessment of places for economic purposes, be it gathering taxes in the past or undertaking economic history in the present. Hilton's work has been highly influential in placing the relationship between town and country into focus, leading to revolutionary insights into the medieval economy (Astill 2009, 265; Dyer 2002, 3; Dyer \& Lilley 2010, 81; Hilton 1992, 17-18; Kowaleski 1995). However, this work has caused the distinction to circulate further as a useful analytical tool in the present, but perhaps masking areas of life where an urban/rural dichotomy is not apparent.

If, however, we removed this pre-conceived dichotomy and worked from the archaeological evidence upwards, a clear distinction between urban and rural would not emerge. Rather, we would see a highly varied spectrum of small and large, nucleated and dispersed, economically diverse and specialized settlements. The category of town is an inheritance; it is a black-box packed through the performance of medieval life, the ongoing categorization of places and the circulation of these categories through particular types of social practice. The process of urbanization can be viewed at multiple scales, being a widespread characteristic of twelfth- to fourteenth-century England, but also taking regional and local forms. Historians such as Britnell (1996) and Dyer (2005) relate the growth of towns to the increasing commercialization of society, fuelled by the export trade and the need to generate increasing seigniorial income to fund royal expenditure on wars. This led to the growth of professions and trades, as well as an increasing pressure to formalize trade through the granting of borough and market charters. The process of borough chartership clearly created a distinctive category of administrative place, but one which, in other areas of life, was not necessarily sharply distinguished from other types of settlement. Urbanization and commercialization are separate but closely related processes. Towns were more than commercial places, and commercial activity took place outside towns. In modern discussions of definition and function, however, the key distinction is between categories of urban and rural place, the primary move having been from a focus on contrast to one on relationality and connectivity (see particularly Kowaleski 1995). I propose, however, that an over-reliance on the urban-rural divide hinders the development of a deeper understanding of the dynamics of medieval society. Therefore, rather than using archaeology to justify the extent to which a place is a town, a further depth can be achieved by unpacking the urban black-box, taking the word 'town' out of circulation and de-constructing it, using the evidence to examine the process of becoming urban and to consider what this means, rather than to assess the state of being urban (see also Christopherson 2015). As demonstrated by Fowler (2013), the aim of archaeological analysis is constantly to critique this received wisdom, to go back to the evidence, to enter into dialogue with it and, although remaining informed by past study, not to be led by it. As Latour $(2005,27)$ argues, the world is constantly in flux and there are no such things as stable categories, just processes of coalescence which emerge and dissolve through action. The action of study has allowed the black-boxed concept of 'town' to continue to circulate and, in doing so, has sent scholarship on a certain trajectory. The aim here is to explore whether, by placing this black-box to one side, by unpacking and re-packaging it, new insights into the process of urbanization (taken in the sense of a national phenomenon of the nucleation and specialization of settlements) might emerge.

It has been argued that towns emerged as a category through the assessment of places for specific purposes. Jones (2012) perceives categories not as $a$ priori distinctions, but as resulting from the emergence of similar entities from repetitive interactions between people and materials, or 'performances'. We can, therefore, expect there to be similarities between these places categorized as towns through various forms of assessment in the recent and distant past; however, archaeological analysis in particular is often guilty of placing a settlement into an a priori category of 'town'. A category is a means of classifying things in spite of their differences and, as such, rigid distinction and categorization might be seen as masking the performative and heterogeneous nature of entities in the past, the variability which is clear when one looks at medieval settlements in depth. Settlements, therefore, can be viewed as repetitive performances of interactions between humans and their surroundings. The performance of a place brings together human and non-human participants, situating them spatially (a similar perspective on the town as performed has been reached by Christopherson 2015). A town (as defined by Dyer 2002) is never at rest: people move around it, materials transform into objects in workshops and 
buildings decay. Towns are not material settings for urban life, nor are they collections of people. Rather, they are vibrant bundles of interactions between people and materials and, as they are constantly in motion, forming and re-forming, 'town' might be considered a verb rather than a noun (Dewsbury et al. 2002). Furthermore, the process of 'towning' or 'becoming urban' might relate only to specific elements of everyday life. Rather than underplaying Hilton's identification of similarities between urban and rural life, perhaps we should emphasize these and, rather than focusing on polarizing categories, explore why certain sets of social relationships became urban and others did not.

\section{Shifting perspectives: medieval towns as assemblages}

So far it has been argued that the term 'town' relates not to a way of being, but to a process of categorization, and that it is through the need to confront and understand patterns of difference in settlement that various, sometimes conflicting, definitions have developed. The aim of the second part of this paper is to develop an approach through which it is possible to understand better how these patterns of difference emerge and their implications for the wider social form of medieval England. This requires an alternative approach, as conventional archaeological analysis might be argued to see the town as a stage or frame for the action of urban life. Whilst we acknowledge that urban form changes with the fortunes of a town (see, for example, Lilley 2015), there remains a fracture between the study of the sociality of urban life and its material manifestation. Materials are taken as providing evidence of the adherence of a place to a preconceived, black-boxed, notion of what a town is. It is clear, however, that the places which we identify as towns are highly varied in size and character. The approach developed here focuses on social relations. Towns are more-than-spatial phenomena; they can be considered as bundles, or assemblages, of social relationships between people, materials and their environment, grounded in physical space but taking a permeable form in which they are entangled with their surroundings. Through the application of this perspective to a specific case study, the urbanization of the Weald of Sussex, the processes of assembling towns and their implications at different scales will be considered. This will build towards an understanding of the town, not simply as a category of place, but as a way of becoming through specific, effective and mutually constitutive relations between people and their surroundings.

\section{Urbanization in medieval Sussex: a summary and an approach}

Sussex is a county situated in southeastern England. By the thirteenth century, it was already partially urbanized. In the southern part of the county, a number of settlements are recognized as towns. Some existed prior to the Norman Conquest of AD 1066, principally developing from late Saxon burhs (defended settlements). Further urban places, primarily ports, developed through the eleventh-twelfth centuries. It is worth pausing briefly to consider some of the elements of these places which have, in the past, been used to define them as urban. These settlements typically have regular street layouts, something which is seen as typical of towns. In Chichester, the street alignment relates to the remnants of the Roman town, whilst in other burhs, such as Lewes, the grid can be seen as having a defensive function (Drewett et al. 1988, 333-9). In these planted settlements, land was granted to local manors and religious institutions, creating a need for the regular division of space. Yet systems of land division and styles of architecture appear similar to those in surrounding rural settlements (see Reynolds 2003). Port towns have a specific function, developing at strategic locations to control trade, forming part of its infrastructure and being one end of a spectrum of landing-places along the coast. Industry gradually shifted from rural estate centres to these new settlements; however, control was still exercised over access to resources, given the tenurial links between town and country. Yet, we can also see, for example in the evidence provided by material culture, the development of distinctive experiences of life in these places (e.g. Astill 2006; Jervis 2014, 110-18). The archaeological evidence demonstrates, therefore, both similarity and difference between these places and contemporary rural settlements.

Following Butler's (1993) discussions of gendered identity, Gregson and Rose $(2000,447)$ argue that places do not pre-exist action, but rather that the performance of social relations brings them into being. Places can be considered to be assemblages of social relations: through activity, assemblages 'take place' (McFarlane 2011). If we view these towns as assemblages, they are not planted stages, populated by people, but rather places which emerged from specific sets of social relationships. In general terms, these relations might include the control of resources through trade and manufacture and the need to defend these resources from Viking raids, which materialized as towns, reiterated through the performance of social life (see also Christopherson's (2015) consideration of towns as performed places). 
This materialization of relationships caused these places to develop along specific trajectories and develop distinctive characters, their form structuring, and being structured by, these performances. These iterative performances reproduced certain normative behaviour and attitudes, which restricted the ways in which social relations could form and might be seen as underpinning the similarities which can be seen both between these settlements and between the towns and contemporary rural sites. However, as bundles of interaction, towns are also effective. They are places where difference could be negotiated at intersections of spheres of interaction, leading to the emergence of particularly urban forms of identity and practice (Christopherson 2015, 130).

It is in this brief consideration of urbanism in late Saxon Sussex that we can begin to see the key elements of an interpretive framework emerging. Firstly, we can see towns as materializations of specific sets of social relations. This process of place-making is mutually constitutive of other urbanizing processes, the 'towning' of people, things and practices. The performance of these relations can be perceived as a process of gathering (Lucas 2012) and is what Deleuze and Guattari $(1987,245)$ term 'territorialization'. Social relations gather a range of actants in a particular location and serve to bind them together. This creates an assemblage which can be identified through the tracing of these relations in the archaeological record, for example the laying out of streets and the division of land. Gathering, however, is a transitory process. The apparent permanence of the town is brought about by the effective nature of these relations. By creating a street grid, dividing land and articulating power through tenurial links, social relations are 'coded' (Deleuze \& Guattari 1987, 47). Deleuze and Guattari $(1987,5)$ perceive a world formed of flows, for example of matter and ideas, which move across a social plane, becoming entangled in random and multiplicitous ways, the processes of territorialization (or gathering) through which assemblages form. These social relations have implications and can be perceived as 'striating' this social space, limiting the ways in which social relations can form (Deleuze \& Guattari 1987, 559-60). This striating of space is the process of coding, the ways in which behaviour is limited and an assemblage re-iterated. There is still space for creativity and change between striations, but within certain bounds. Therefore, the performance of social relations was both reproduced and constrained by normative behaviour, rules, regulation and the residues of past action. Furthermore, this coding might be seen as pushing these entangled flows along certain trajectories, exacerbating specific social processes. Lilley (2000), for example, has demonstrated how the form of some Anglo-Norman towns in Wales and Ireland served to marginalize local populations. This marginalization can be seen as coded through the layout of urban space, becoming increasingly exacerbated with every performance of urban life from which these people were excluded.

When thinking through the process of urbanization, therefore, we can use these concepts of territorialization and coding to perceive how the process of becoming urban emerges through iterative gatherings. As will be discussed later, urbanization occurred at multiple scales, coding action (or striating space) in a stratified way with implications for new and existing settlements.

The focus of this paper is a second wave of urbanization in Sussex, which principally occurred in the thirteenth-fourteenth centuries in an area in the northern part of the county, known as the Weald (Fig. 1). This is an area which was sparsely settled in the pre-Conquest period, but was gradually cleared of dense woodland through the medieval period (Brandon 1969, 135-42; Chatwin \& Gardiner 2012; Gardiner 1996). Settlement was largely dispersed, with towns forming distinctive nucleated foci. Here the first town to develop was Battle, in the eleventh century (Searle 1974, 69; James 2008), with further towns developing at East Grinstead (Leppard 1991), Crawley (Stevens 1997; 2008), Horsham (Stevens 2012) and Robertsbridge (Gardiner 1997a) in the thirteenth-fourteenth centuries. There is also an ambiguous class of nucleated settlements, termed by Gardiner (1997b) 'substitute towns'. These are places which served as central economic foci for dispersed rural communities, but without many of the characteristics which might be seen as typical of a fully-fledged town. It is these ambiguous settlements, as well as the fact that the Weald was sparsely settled in the Anglo-Saxon period, that makes it a suitable area for developing new frameworks for examining urbanization. The following discussion is broken into three sections. The first examines the processes of gathering and coding through which these places emerged; the second explores the relationship of settlement foundation to the surrounding landscape, discussing the issue of scale and introducing the concept of de-territorialization; and the final section considers the implications of this approach for shifting towards a focus on becoming, rather than being, urban.

\section{Gathering assemblages}

Urbanization might be considered to develop at the intersection of two different scales of social process. The 


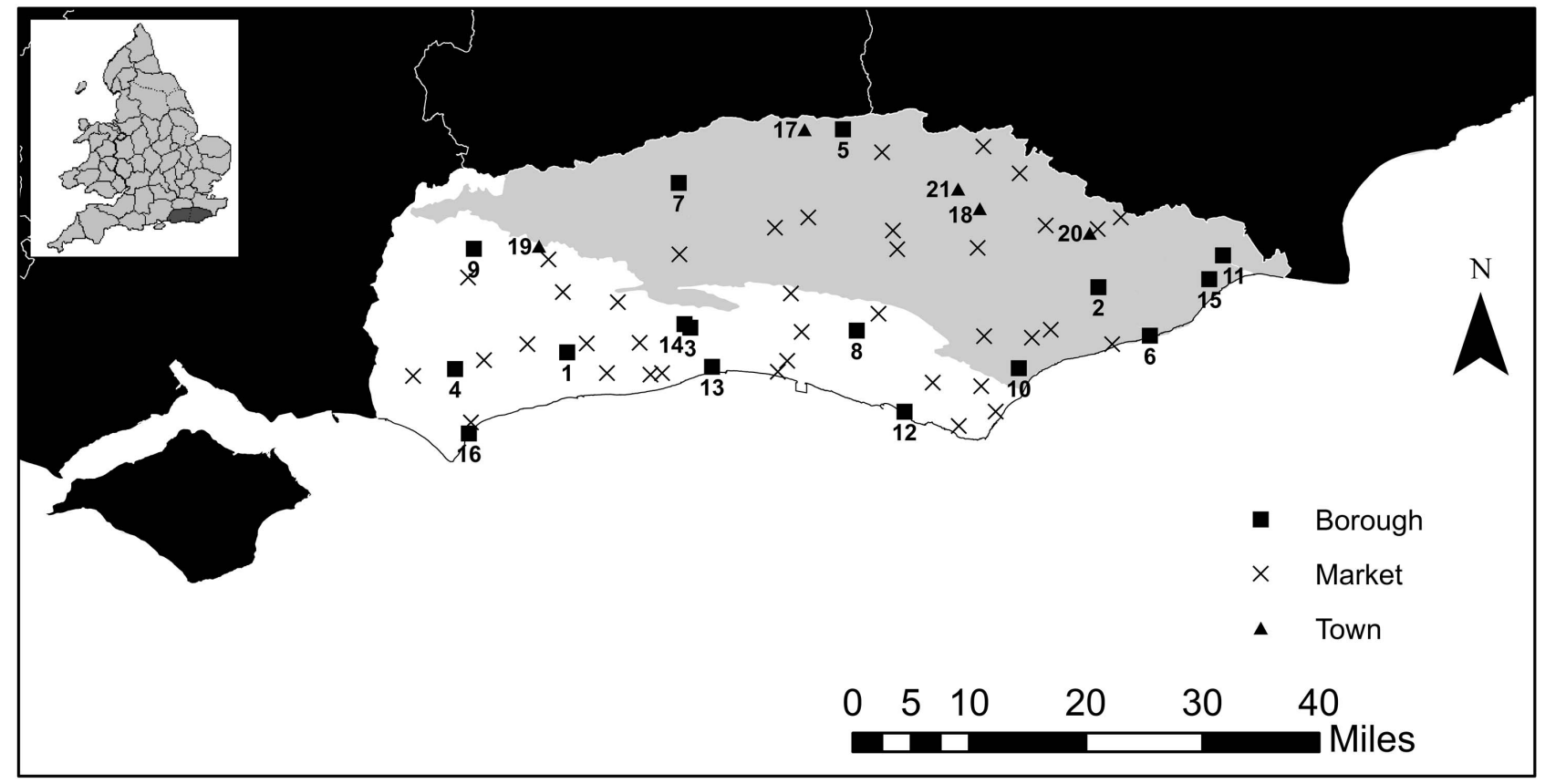

Figure 1. The location of towns and markets in Sussex. The area in grey is the Weald.

Boroughs: 1: Arundel; 2: Battle; 3: Bramber; 4: Chichester; 5: East Grinstead; 6: Hastings; 7: Horsham; 8: Lewes; 9: Midhurst; 10: Pevensey; 11: Rye; 12: Seaford; 13: Shoreham; 14: Steyning; 15: Winchelsea; 16: Withering.

Towns (urban places with market charters): 17: Crawley; 18: Mayfield; 19: Petworth; 20: Robertsbridge; 21: Rotherfield.

decision to plant a town formally, that is, through the acquisition of a borough or market charter, was generally that of the lord holding a manor or estate. In general terms a lord may have had several motivations, chiefly economic: the need to generate revenue to pay increased taxes arising from royal expenditure, a desire to retain revenue from the marketing of surplus from their estate, and to generate tolls from marketing activity (Britnell 1996, 121). In the Sussex context a further motivation can be suggested. The pattern of landholding in Sussex is considerably less fragmented than in many areas of the country. The county was divided into five north-south divisions, known as rapes. Each rape was the possession of a lord, whose seat was situated in a port town. Across the rape a variety of different landscape zones were present, providing different resources and lending themselves to different types of agricultural regime. The foundation of towns in the Weald by these lords or their associates, for example at East Grinstead (rape of Pevensey), Crawley (rape of Lewes) and Horsham (rape of Bramber), may suggest the establishment of a marketing system in which the full resources could be managed and processed. At this scale, therefore, town foundation can be seen as an instrument of estate management (see also Goddard 2011), emerging from top-down economic pressures.
A focus on lordship alone is misleading, implying that towns are the result of human agency and intentionality. Intentionality alone, however, does not equate to outcomes. By acting out intentionality, lords acted upon existing networks of social relations, the outcomes emerging as an effect of this process. If we take a view of agency as emerging from social interaction, as a property of relations (Bennett 2010, 24; Latour 2005, 63; see Jones \& Boivin 2010 for a review of approaches), then towns are not a means of seigniorial expression, but rather a product of networks of power in elite medieval society, perhaps most fundamentally the tax burdens recognized as driving medieval commercialization (Britnell 1996, 121; Hilton $1985,7)$. More accurately, it is not the town which emerges from this process, but the borough or market charter. Documents such as charters can be considered a form of black-box; they code social relations through their relationship with other legal documents (Latour 2010), for example those which decree that marketing can only take place in recognized locations. A charter is more than a document: it is the materialization of an assemblage of lordship, which, through being enrolled into the performance of particular courses of action, principally the marketing of resources, served to limit, or code, this action, focusing it on specific places in the landscape. 
Examples of 'failed' towns show that the process of town foundation is about more than a charter (see Beresford 1967, 290-302). The foundation of nucleated settlements (including towns) in the Weald appears related to places in the landscape which were already important locations of gathering (Gardiner 1997b, 65). East Grinstead, for example, is identified as a hundred meeting place (Leppard 1991, 31). Churches and hundred meeting places attracted regular gatherings and became places of exchange; in many cases in the Weald markets appear to precede permanent settlement (see also Dyer 2003, 98, for a general discussion of the relationship between towns and existing landscape features). For other places, such as Crawley, there does not seem to have been such a history of regular formal assembly, but its situation at a crossing of north-south and east-west routes, at an administrative boundary (between the rapes of Bramber and Lewes), suggests that it may have formed a nodal point in the landscape (Stevens 1997, 193). Roads through the Weald were sparse and therefore traffic through this dense woodland was channelled along particular routes (Gardiner 1997b, 70; Searle 1974, 46). Prior to the formalization of markets through charters, we can perceive of flows of movement through the landscape. These built towards repeated processes of assembly which made these places, and associated communities, persistent (De Landa 2006, 36). These processes of assembly leave little archaeological trace. Examples might be small quantities of pre-twelfth-century pottery recovered from excavations in Crawley (Stevens 2008).

The agency for town foundation emerges at the intersection of this assemblage of lordship (which might be considered one driver of the national trend towards urbanization and commercialization) and local processes of gathering. Christopherson $(2015,119)$ highlights a contrast between top-down, processual approaches to urbanism and post-processual, bottomup approaches. What the approach taken here demonstrates is that these need not be mutually exclusive (Fleicher 2015, 134); lordship is as important as more banal social interactions, with change emerging when these different spheres of interaction collide. This has implications for thinking about the spatiality of power in the landscape. Rather than expressions of seigniorial or communal power, we can see towns as a negotiation of power relations, as creating new power structures both internally (e.g. civic government) and regionally, as the formalization of towns furthered their existing role as foci of gathering, crystallizing territories which emerge with town foundation, but out of congealed historical action.
These repeated processes of gathering both emerged from and generated wider sets of social, economic and political relations. They caused places to persist in the landscape, with past action constraining how people and goods could flow across it and interact with each other. The presence of Roman roads, the division of land into hundreds and the establishment of parishes are all examples of the past interactions which had striated space in both a physical and a conceptual way. People and things were directed across the landscape, whilst administrative divisions drew people to particular gathering places in preference to others. As McFarlane $(2011,654)$ states, assemblage thinking 'emphasizes the depth and potentiality of sites and actors in terms of their histories'; it forces us to think about not just what phenomena emerged from, but the processes through which this occurred. Once established as gathering places, structures such as churches, landmarks denoting meeting places or road junctions colonized as markets became foci of citational behaviour, recognized as locations for the playing out of particular sets of social relations which reiterated their significance. We can see, therefore, how these places, through the coding brought about by past action, emerged with wider territories (De Landa 2006, 104); they emerged both as persistent and central places within the landscape.

Prior to town foundation, these places were already mediating the emergence and reiteration of communities (see Harris 2014 for a discussion of this concept). As these places were formalized, for example through the granting of charters, a shift in the regional dynamic of power can be perceived, as a neutral gathering place became a regulated centre of production and marketing. Commercial relations were formalized, changing how people perceived themselves through the performance of this activity, what we might view as the emergence of specifically urban forms of identity, or a 'towning' of the self. As discussed below, it is through this process that we see a sharp distinction emerge between urban and rural and the reformulation of communities; with a process of becoming urban came a process of becoming rural. As Hilton (1992, 10-14) demonstrates, in both town and country power structures were similar and, rather than seeing this process as enfranchising urban communities and excluding rural ones, we can see the specialization and intensification of a commercial network, in which specialized people and places emerged. However, bonds of mutual reliance ensured that connections were retained between town and country. The urban market became a location in which urban and rural social networks intersected with each other, in which difference was negotiated 
and the town emerged as a particular type of place through marketing interactions.

Even within the three towns associated with the lords of the rapes or other major landowners, distinctions can be seen. Crawley is a market rather than a borough for example, implying that Michael de Poynings, who acquired the charter, was not willing to give the inhabitants the full freedoms enjoyed by those living in Horsham and East Grinstead. This may be because, as archaeological excavation demonstrates (Cooke 2001; Stevens 1997; 2008), Crawley functioned principally as a site for the processing of iron and it was desirable to retain some seigniorial control over this resource. Market charters are also a characteristic of the so-called 'substitute towns', which developed principally on land belonging to the crown (e.g. Rotherfield) or to the Archbishop of Canterbury (e.g. Wadhurst, Uckfield and Mayfield: see DuBoulay 1966, 125, 137) (Fig. 2). These settlements appear to have developed at similar kinds of central places, with informal plots surrounded by demesne land developing around market places and market charters serving to formalize existing commercial activity (Gardiner 1997b, 71). Monastic and royal estates were managed for different reasons to seigniorial ones; often produce was intended for consumption by landowners, with varying proportions being marketed (Hare 2006). Within this context borough privileges were not appropriate, but there were benefits to being able to profit from existing marketing. Tenurial geography was such that these central places were parts of different constellations of relations. As with the seigniorial towns it can, however, be argued that market settlements emerged at the intersection between two scales of interaction, the local and the administrative.

Deleuze $(1995,160)$ states that it is not 'beginnings and ends that count, but middles'. It is this emphasis of the middle that a consideration of towns as processes brings out. Urbanization is one event in a longer trajectory of place-making, emerging from existing, iterative, processes of gathering which code action and striate social space. The agency for change emerges when existing networks of interaction collide. If we see gathering and re-iteration as performances, then 'performativity is about connection' (Dewsbury 2000, 476). We can see that through the connection of different territorialized sets of actions (or assemblages) new things, boundaries, territories and places emerge. Seigniorial boroughs emerge from the collision of elite networks and localized performances of place and substitute-towns through similar collisions with different tenurial networks. This illustrates how towns emerged from different sets of relations, a national phenomenon, negotiated locally at the intersection of scales and realms of interaction. It is from here that we can progress to think more about these collisions, through a discussion of deterritorialization and scale.

\section{Extending place: de-territorialization and scale}

Scale has emerged as a key point of discussion. In one sense urbanization can be viewed at multiple scales, from an (inter)national phenomenon with regional variants to the individual experiences of households and people who were transformed from a rural to an urban way of life. In another sense, action can be perceived as stratified, in the manner described by Deleuze and Guattari (1987, 46-7). For them, assemblages are formed of other assemblages and interactions can reverberate between scales. These scales are not neatly nested into each other, but are enfolded with one another. If we think of an assemblage as constituted of a variety of actants, then each actant is an assemblage in itself. Each actant might, simultaneously be a part of other assemblages, a process termed de-territorialization, as through these actants, assemblages extend beyond themselves. It is this process of de-territorialization that enfolds scales. An example is the borough charter discussed above: it is simultaneously part of the assemblage of medieval elite society and of the place to which it relates; it de-territorializes the local performance of place, folding it into the national web of interactions through which we can perceive a broader process of urbanism. Therefore assemblage theory becomes a useful tool for overcoming the divide between local and larger-scale studies of town foundation (see also Allen 2011, 277; Latour 2005, 173).

Our settlements are themselves stratified assemblages: each is formed of households and individuals, but is a part of larger assemblages which are the rapes, estates, Sussex and local, regional and national urban networks, for example. These assemblages are not discrete, but overlap with one another, the town being articulated differently through enrolment in these networks. This demonstrates the key point from the first section of this paper, that 'town' is not a single category of place, but rather a mode of becoming which occurs through enrolment in these different sets of interactions. The current section explores this contention further, through a consideration of the relationship between our towns and their rural surroundings and their place within regional urban networks.

Excavations in Crawley demonstrate that in the thirteenth century, iron production became an urban industry. This shift was accompanied by an intensification of output, with the close relationship 


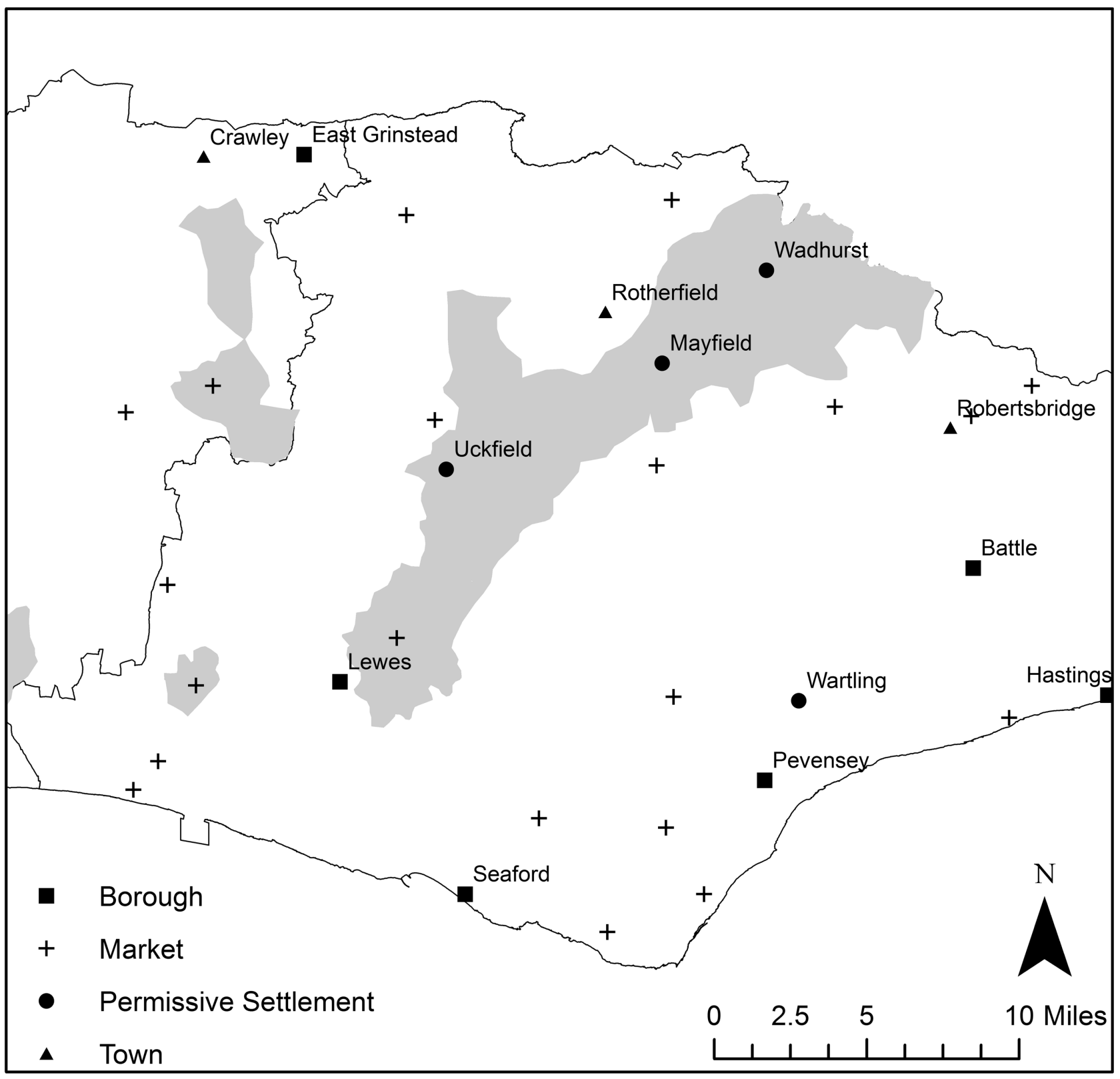

Figure 2. Market foundations on the Wealden estate of the Archbishop of Canterbury (grey area).

between producer and market, and the concentration of production on the estate in a single centre. Iron, then, was an actant in the reiteration of Crawley, but was enrolled in multiple other processes of assemblage as it was put to use. The product deterritorialized the industry: iron might be considered an assemblage convertor (Deleuze \& Guattari 1987, 378), a medium through which localized interactions between people and materials are joined to interactions and processes occurring in different places, at different speeds. Objects and materials offer a means of mediating social relationships across scales, folding the 'global' or non-local processes into personal, small-scale performances (Bennett 2010, 42). It was this de-territorialization which caused externalities to act upon the process of iron production. Increased demand from the army and the London market meant that production needed to intensify, with producers devoting more time to iron working (Cleere \& Crossley 1985, 89-91; Hodgkinson 2008, 37). Here, then, we can see another confrontation of scale, between localized production and external demand, with the 
agency for change emerging in this coming together. Iron production did not occur in isolation. Coupled to the intensification of the iron industry was the greater management of woodland resources and clearance for agriculture. Timber was a valuable trade resource and wood also had to be managed for fuel (Galloway et al. 1996; Gardiner 1996, 123; Pelham 1928). Some evidence of coppicing and woodland management can be seen in the wood fuel remains from excavations in Crawley (Stevens 2008, 141). This clearance created further demand for iron tools (Hodgkinson 2008, 37). The de-territorialized nature of iron enrolled it in multiple processes of change. As an industrial resource, like cattle required for leather production (see Brandon 1969, 149; Saunders 1998; Searle 1974, 5, for evidence of tanning in towns), it mediated the relationship between the intensification of agricultural activity and the intensification of production. Both industries 'became urban' as conflicting demands on land, labour and resources led to the emergence of increased specialization, as part of a commercializing economy.

In this specialization, we see the negotiation of the polarized divide between town and country, with towns becoming Beresford's (1967, 55-6) 'specialized centres of making and dealing'. But these production processes were neither exclusively urban nor rural. The urban processing of rural resources created a dialogue which made a firm divide between town and country untenable, if we base our understanding on social connections rather than the spatial differentiation of activity. In this light, we might argue that that the settlement is a less useful frame for analysis than seeking to understand the system and the interconnections between different activities through which specialization emerged and became focused in specific locations. As Jones and Sibbesson (2013) argue for the emergence of the Neolithic, we can perceive of multiple, entangled, trajectories of action, with the agency for change emerging at their intersections. In this context iron production and agriculture might be perceived of as two such trajectories. Urban character developed out of these intersections, rather than being bestowed upon a place through the act of foundation. It was in the performance of social practice that people, places and things became urban, as towns were actualized through processes of assemblage. That is to say, urbanity was not a given property of a place, but was re-iterated and improvised. Urbanism is not defined as a set of characteristics, but as a quality defined in relation to other ways of becoming that emerged out of alternative entanglements of these courses of action, resulting in multiple forms of both urban and rural experience.
Urbanization was, therefore, part of a wider economic change, what might be termed commercialization, which was negotiated through changing relationships with resources. The presence of informal markets set places on trajectories through which marketing activity intensified, was formalized, and became enrolled in the performance of places which were distinct from both other places and the places that they had been. The presence of chartered markets 'overcoded' the existing system of informal markets and dispersed settlement (Deleuze \& Guattari 1987, 71-3). Urban places, as sets of social relations, emerged out of previous performances, and were effective in that they generated new relations, as well as reiterating existing ones, which distinguished them from other places. Social space was further striated, but with certain constraints (the need, for example, to undertake multiple forms of economic activity in an unspecialized economy) being smoothed and a new form of social space, in which a distinction between town and country was perceptible, emerging.

Dewsbury $(2000,477)$ argues that it is at points of rupture, where performance is disrupted, that we reveal ourselves, as it is in these situations that renegotiation takes place. Therefore, it is at points of change and rupture that towns reveal themselves as a distinctive entity, as urbanism comes to be defined in relation to other modes of becoming. There are, however, elements to Crawley which are distinctly rural. Fields were laid out with the town and industry was seemingly organized at a household scale (Cooke 2001; Stevens 2008, 145). But in the performance of production and marketing it is revealed as a different kind of place to those which surround it. It became urban as the processes which constituted it as a place changed and caused its position in relation to other places, its region, people and resources to be re-negotiated. Importantly, allied to this process, we can see other places as becoming rural. Whereas in the Wealden context dispersed settlements had been normal, commercialization brought about a point of rupture, in which they are revealed as different to the emerging urban centres, and in which the performance of these places takes them on a divergent trajectory, as specialized producers and managers of resources. At the time of urbanization, therefore, we see an intensification of occupation and agricultural activity, a shift in the economy of the region to one based on small-scale, specialized, production. This colonization of the woodland transformed it from a wild to a managed landscape, a process of which urbanization was one part.

This consideration of the relationship between towns and their surroundings brings us to the wider 
commercial networks within which these settlements participated. The full range of pre-urban commercial connections in the Weald is difficult to re-construct owing to the limited number of excavations and the small number of finds recovered from them. With the intensification of the management of rural resources and production came the intensification of commercial activity. The coastal ports were conduits for Wealden products, particularly timber (Pelham 1928). Pottery production centres developed around the fringes of the Weald, their position determined in part by access to markets (Gardiner 1990, 49). Pottery from Surrey, presumably transported through the Weald, appears at coastal sites. Finds of French pottery in Horsham (Stevens 2012) and Crawley (Stevens 1997) perhaps hint at return trade. The pre-urban markets were already nodes in commercial networks, the flow of goods around Sussex was already coded, causing trade to take place in particular places and not in others. The Wealden towns therefore emerged in relation to these existing urban centres. Whilst towns were not direct copies of others, existing urban structures acted on the form that new towns took. This was not so much a case of copying street layouts, but rather ways of dividing space, assigning land and doing business (cf. discussion by Lilley (2010) of towns in Devon and Hampshire). The differences between religious and seigniorial foundations in terms of liberties (the granting of borough or market charters) demonstrates an enfolding of scale, as marketing centres were founded in relation to estates, whilst taking the form of other settlements which emerged through similar processes.

Processes of urbanization in one town were connected to those in other towns, a point well demonstrated by Sindbaek (2007), who shows how exchange networks mediate the emergence of different types of urban place. These marketing connections deterritorialize towns, with action in one place having implications for others. Therefore, urban processes in a single place can be seen as enfolded with those in other places at a regional scale. This has two implications: firstly, activity in one town cites that in others, creating a category of places joined through the performance of similar forms of commercial activity; secondly, we can see new forms of urban sociality emerging as towns became sites of negotiation between the local networks discussed earlier in this section and wider commercial networks. The very relationships which constitute towns also de-territorialize them, forcing them into relations with other towns and markets. Links to south coast ports and to London simultaneously contributed to the coming together of these places, but also situated them within eco- nomic networks. Increased demand for Wealden iron pulled them into supra- regional networks of supply and consumption. The impact of major events, such as warfare, became localized through the deterritorialization of iron, having a transformative effect on the towns, driving them towards more intensive production and more explicit differentiation from surrounding settlements. These were not networks through which goods simply passed, but were performative, transformative networks in which activities such as trade mediated processes of becoming urban at multiple scales. This was not in the sense of adhering to a particular urban template, but rather a process of transformation in which urban assemblages take on the appearance of other, similar places, and become distinguished from their surroundings. Furthermore, as urbanism was performed at different scales, so various experiences of urban life, multiple urbanisms, occurred as people became urban through their enrolment in different zones of the assemblage.

By looking at the material actants enrolled in the constitution of urban places, we can see how towns are not separated from wider society, but emerge with other forms of sociality. Whilst urbanism gathered actants in processes of making and trading, it also de-territorialized the town, causing ruptures in traditional ways of doing through which a contrast between urban and rural becomes visible. It is in these moments of rupture that we can perceive a category of town emerging. This process of becoming urban is allied with, in the Weald, processes of becoming rural, as part of a wider commercializing and managing of the landscape. Town and country cannot, therefore, be separated in a processual sense as they define each other; processes of becoming urban are enmeshed in processes of becoming rural. These actants are the media through which scales are enfolded, as demand in distant places pulled local performances of gathering in the market into wider processes driven by factors such as taxation and warfare. The assembly of the town, therefore, flowed beyond its physical borders; through networks of interaction spatial and commercial territories emerged into which the town was de-territorialized (see De Landa 2006, 104). These might be classed as hinterlands, but rather than seeing towns as controlling these spaces, I am arguing for spaces emerging which are defined in relation to these new centres. As they become urban, so people become affiliated with a market, enter into regional networks of commercial interaction and are enrolled in processes which over-code existing social relations. Through these interactions towns form, becoming an active presence in the social landscape. 


\section{Multiple urbanisms}

This paper began with a discussion of issues surrounding the definition and recognition of towns and has gone on to highlight the variation amongst places which we might categorize as urban. It has been argued that, rather than focusing on the town as an entity, a deeper understanding might emerge if we focus analysis on the processes through which social change was mediated and friction between scales articulated. This analysis leads to a contention that not only do different forms of urbanism exist, but that if urbanism emerges at intersections between assemblages (as argued, for example, in the case of the iron industry), towns emerge through various forms of discourse (McFarlane 2011, 652). Both urbanization and its related process of commercialization can be considered as wide-scale processes formed through localized interactions. Elsewhere towns also formed in similar ways, as coalescences of associations, but did not form a single type of town but multiple forms of urban assemblage, manifesting as various forms of urban identity and sociality (Thrift 2007,161). It is less that we can create a typology of towns, but more a case that people assemble their own urbanisms as they experience and partake in social relations; towns are not found, but are actualized as they are enacted within an assemblage (Dewsbury 2000, 482; McFarlane 2011, 665). As discussed above, it is at points of rupture that towns reveal themselves. This is as much the case in the division between urban and rural which emerges in the Weald in the thirteenth century as in the tax assessments discussed by Masschaele (1997), where towns reveal themselves through an inability to be taxed on agricultural produce. Following Butler (1993) and Gregson and Rose (2000), it was argued that towns are not stages for action, but are produced through performances. Therefore, towns are not inhabited, but are produced through dwelling in space (McFarlane 2011, 651), emerging through specific forms of relationship which cause tears in the social fabric and reveal difference. Being urban is, therefore, not a characteristic of a place; urbanism is a property which emerges through social interactions. Industry becomes urban as it enacts a divide between towns and other places, just as other activities, such as the cultivation of fields in Crawley, appear to transcend the urban and rural divide. Rather than focusing at a simple level on similarities and differences between rural and urban life, or particular sites, an assemblage approach allows us to de-territorialize our site, follow the flows and the relationships which constitute it and understand how contrasts emerge through which urban places reveal themselves. In other words, we can work from the ev- idence to trace the areas of medieval society in which urbanism is significant and those in which it is not, rather than taking as a starting-point that a place is a town and that we should, therefore, expect certain things of it.

We can push this argument further still, to question whether places are always towns. If we view places as reiterated through performance, and determine that urbanism reveals itself through certain sets of social relations and not through others, we can view urbanism as something of a flicker, rather than a constant. The processes which weave the fabric of a place are transformative, but do not shift a place to an urban state; rather they cause urban qualities to surface. These processes are the medium through which a place becomes urban, but perhaps also, as they cease, might be perceived as processes of unbecoming, as ruptures heal over and the distinctions that they bring about dissolve. Over the longer term, ruptures are apparent in the different trajectories that places take, creating a spectrum of urban places. Urban trajectories can be perceived at the national scale, but locally we can see different forms of coding emerge, the social spaces of settlements and regions being striated as places are deterritorialized in different ways, manifesting as the contrast between boroughs and substitute towns, for example. As the processes that cause ruptures are exacerbated, so the presence of urban qualities becomes more vivid. Perhaps, then, the reason that towns are so elusive is that they are emergent, coming into view in different ways through different processes, of which historical and archaeological research is just one.

\section{Conclusion}

This paper set out to utilize assemblage theory to develop new perspectives on processes of urbanization in medieval England. Principally this entailed moving from understanding 'urban' as a state of being, to a state of becoming, to highlight the varying forms and roles taken by places that we recognize as towns in the medieval past. The consideration of town as an analytical black-box served to demonstrate that categories emerge through action, and this was developed further when it was argued that towns appear at points of rupture in social practice. By viewing the town relationally, several key conclusions have been reached. Firstly, towns reveal themselves as the performance of relationships between scales of interaction creates difference. Secondly, these processes of emergence have implications, as action comes to be coded and places develop along trajectories, in which they 
demonstrate similarity to some places and difference from others. Thirdly, we might also perceive of performances in which the town is not revealed, or in which different forms of distinction are revealed as significant. As a flickering quality urbanism is revealed through certain interactions, but not through others. This has implications for the practice of writing urban archaeology, and settlement archaeology more generally. If we see places as relational, then we must extend our analysis beyond the site to consider how it relates to other places, and how processes lead to the emergence of distinction and similarity. Focusing on emergence through processes is fundamentally different from seeking to identify signatures of urban or rural activity. Indeed, the frustration of attempting to do so stimulated the change of approach discussed here. It follows, therefore, that rather than seeking to classify places in accordance with historical systems of categorization, emerging out of particular sets of practice, categories must be seen as emerging through performances at different scales to consider how social processes of commercialization and urbanization might be considered to have been articulated locally, regionally and nationally. In conclusion, therefore, this study calls for a reappraisal of how we do urban archaeology, moving from a focus on urban places to processes of 'towning' or 'becoming urban' to appreciate the ways in which the places that have been identified as towns diverge from other places.

$$
\begin{array}{r}
\text { Ben Jervis } \\
\text { History, Archaeology E Religion } \\
\text { Cardiff University } \\
\text { John Percival Building } \\
\text { Colum Drive } \\
\text { Cardiff CF10 3EU } \\
\text { UK } \\
\text { Email: jervisb@cardiff.ac.uk }
\end{array}
$$

\section{References}

Allen, C., 2011. On Actor-Network Theory and landscape. Area 43(3), 274-80.

Ashby, S., A. Coutu \& S. Sindbaek, 2015. Urban networks and Arctic outlands: craft specialists and reindeer antler in Viking towns. European Journal of Archaeology 18(4), 679-704.

Astill, G., 1985. Archaeology and the smaller medieval town. Urban History Yearbook 46-53.

Astill, G., 2006. Community identity and the later AngloSaxon town: the case of southern England, in People and Space in the Middle Ages 300-1300, eds. W. Davies, G. Halsall \& A. Reynolds. Turnhout: Brepols, 233-54.

Astill, G., 2009. Medieval towns and urbanization, in Reflections: 50 years of medieval archaeology, eds. R. Gilchrist
\& A. Reynolds. (Society for Medieval Archaeology Monograph 30.) Leeds: Maney, 255-70.

Bennett, J., 2010. Vibrant Matter: A political ecology of things. Durham (NC): Duke University Press.

Beresford, M., 1967. New Towns of the Middle Ages. Cambridge: Cambridge University Press.

Biddle, M., 1976. Towns, in The Archaeology of Anglo-Saxon England, ed. D. Wilson. London: Methuen.

Brandon, P., 1969. Medieval clearances in the East Sussex Weald. Transactions of the Institute of British Geographers 48, 135-53.

Britnell, R., 1996. The Commercialisation of English Society 1000-1500. Cambridge: Cambridge University Press.

Butler, J., 1993. Bodies That Matter. London: Routledge.

Chatwin, D. \& M. Gardiner, 2012. Rethinking the early medieval settlement of woodlands: evidence from the western Sussex Weald. Landscape History 27(1), 31-49.

Christopherson, A., 2015. Performing towns. Steps towards an understanding of medieval urban communities as social practice. Archaeological Dialogues 22(2), 109-32.

Cleere, H. \& Crossley, D., 1985. The Iron Industry of the Weald. Leicester: Leicester University Press.

Cooke, N., 2001. Excavations on a late medieval ironworking site at London Road, Crawley, West Sussex, 1997. Sussex Archaeological Collections 139, 147-67.

De Landa, M., 2006. A New Philosophy of Society. Assemblage theory and social complexity. London: Bloomsbury.

Dewsbury, J-D., 2000. Performativity and the event: enacting a philosophy of difference. Environment and Planning D: Society and Space 18, 473-96.

Dewsbury, J-D., P. Harrison, M. Rose \& J. Wylie, 2002. Enacting geographies. Geoforum 33, 437-40.

Deleuze, G., 1995. Negotiations. New York (NY): Columbia University Press.

Deleuze, G. \& F. Guattari, 1987 (trans. 2013). A Thousand Plateaus. London: Bloomsbury.

Drewett, P., D. Rudling \& M. Gardiner, 1988. The South-East to $A D$ 1000. London: Longman.

Du Boulay, F., 1966. The Lordship of Canterbury. An essay on medieval society. London: Nelson.

Dyer, C., 2002. Small places with large consequences: the importance of small towns in England, 1000-1540. Historical Research 75(187), 1-24.

Dyer, C., 2003. The archaeology of medieval small towns. Medieval Archaeology 47, 85-114.

Dyer, C., 2005. An Age of Transition? Economy and society in England in the Later Middle Ages. Oxford: Oxford University Press.

Dyer, C. \& K. Lilley, 2010. Town and countryside: relationships and resemblances, in Medieval Rural Settlement. Britain and Ireland, AD 800-1600, eds. N. Christie \& P. Stamper. Oxford: Oxbow, 81-98.

Egan, G., 2005. Urban and rural finds: material culture of country and town, c. 1050-1500, in Town and Country in the Middle Ages, eds. K. Giles \& C. Dyer. (Society for Medieval Archaeology Monograph 22.) Leeds: Maney, 197-210. 
Fleicher, J., 2015. On critical approaches, unintended consequences and the data of everyday life in 'performing towns'. Archaeological Dialogues 22(2), 132-6.

Fowler, C., 2013. The Emergent Past. A relational realist archaeology of Early Bronze Age mortuary practices. Oxford: Oxford University Press.

Galloway, J., Keene, D. \& Murphy, M., 1996. Fuelling the city: production and distribution of firewood and fuel in London's region, 1290-1400. Economic History Review 69(3), 447-72.

Gardiner, M., 1990. The archaeology of the Weald - a survey and review. Sussex Archaeological Collections 128, 3353.

Gardiner, M., 1996. The geography and peasant rural economy of the eastern Sussex High Weald, 1300-1420. Sussex Archaeological Collections 134, 125-39.

Gardiner, M., 1997a. Fieldwork and excavation on the Robertsbridge bypass, 1985. Sussex Archaeological Collections 135, 301-10.

Gardiner, M., 1997b. Trade, rural industry and the origins of villages: some evidence from south-east England, in Rural Settlements in Medieval Europe, eds. G. De Boe \& F. Verhaeghe. (Papers of the 'Medieval Europe Brugge' conference 1997, vol 6.) Zellik: I.A.P. Rapporten, 6373.

Goddard, R., 2011. Small boroughs and the manorial economy: enterprise zones or urban failures? Past and Present 210, 3-31.

Gregson, N. \& G. Rose, 2000. Taking Butler elsewhere: performativities, spatialities and subjectivities. Environment and Planning D: Society and Space 18, 433-52.

Hare, J., 2006. The bishop and the prior: demesne agriculture in medieval Hampshire. Agricultural History Review 54(2), 187-212.

Harris, O., 2014. (Re)assembling communities. Journal of Archaeological Method and Theory 21, 76-97.

Hilton, R., 1985. Medieval market towns and simple commodity production. Past and Present 109, 3-23.

Hilton, R., 1992. English and French Towns in Feudal Society: A comparative study. Cambridge: Cambridge University Press.

Hodder, I., 2012. Entangled: An archaeology of the relationships between humans and things. Oxford: Wiley.

Hodgkinson, J., 2008. The Wealden Iron Industry. Stroud: The History Press.

James, R., 2008. Excavations at the Jenner and Simpson Mill site, Mount Street, Battle, East Sussex. Sussex Archaeological Collections 146, 149-73.

Jervis, B., 2014. Pottery and Social Life in Medieval England: Towards a relational approach. Oxford: Oxbow.

Jones, A., 2012. Prehistoric Materialities. Becoming material in prehistoric Britain and Ireland. Oxford: Oxford University Press.

Jones, A. \& N. Boivin, 2010. The malice of inanimate objects, in The Oxford Handbook of Material Culture Studies, eds. D. Hicks \& M. Beaudry. Oxford: Oxford University Press, 333-51.
Jones, A. \& E. Sibbesson, 2013. Archaeological complexity: materials, multiplicity and the transitions to agriculture in Britain, in Archaeology After Interpretation: Returning materials to archaeological theory, eds. B. Alberti, A. Jones \& J. Pollard. Walnut Creek (CA): Left Coast Press, 151-76.

Kowaleski, M., 1995. Local Markets and Regional Trade in Medieval Exeter. Cambridge: Cambridge University Press.

Latour, B., 2005. Reassembling the Social. An introduction to Actor-Network Theory. Oxford: Oxford University Press.

Latour, B., 2010. The Making of Law. London: Polity Press.

Leppard, M., 1991. East Grinstead before the town. Sussex Archaeological Collections 129, 29-32.

Lilley, K., 2000. 'Non urbe, non visco, non castris': territorial control and the colonization and urbanization of Wales and Ireland under AngloNorman lordship. Journal of Historical Geography 26(4), 517-31.

Lilley, K., 2010. Urban planning and the design of towns in the middle ages: the Earls of Devon and their 'new towns'. Planning Perspectives 16, 1-24.

Lilley, K., 2015. Urban planning after the Black Death. Urban History 42(1), 22-42.

Lucas, G., 2012. Understanding the Archaeological Record. Cambridge: Cambridge University Press.

Masschaele, J., 1997. Peasants, Merchants and Markets: Inland trade in medieval England 1150-1350. New York (NY): St Martin's Press.

McFarlane, C., 2011. The city as assemblage: dwelling and urban space. Environment and Planning D: Society and Space 29, 649-71.

Pearson, S., 2005. Rural and urban houses 1100-1500, in Town and Country in the Middle Ages, eds. K. Giles \& C. Dyer. (Society for Medieval Archaeology Monograph 22.) Leeds: Maney, 40-60.

Pelham, R., 1928. Timber exports from the Weald during the fourteenth century. Sussex Archaeological Collections 69, 170-82.

Reynolds, A., 2003. Boundaries and settlements in late sixthto eleventh-century England, in Boundaries in Early Medieval Britain, eds. D. Griffiths, A. Reynolds \& S. Semple. (Anglo-Saxon Studies in History and Archaeology 12.) Oxford: Oxford University School of Archaeology, 98-139.

Reynolds, S., 1977. An Introduction to the History of Medieval English Towns. Oxford: Oxford University Press.

Saunders, M.J., 1998. Archaeological investigations on the route of the Crawley High Street Relief Road, Crawley, West Sussex. Sussex Archaeological Collections 136, 8194.

Searle, E., 1974. Lordship and Community. Battle Abbey and its banlieu 1066-1538. Toronto: Pontifical Institute of Mediaeval Studies.

Sindbaek, S., 2007. Networks and nodal points: the emergence of towns in early Viking Age Scandinavia. Antiquity 81, 119-32. 
Stevens, S., 1997. Excavations at the Old Post Office Site, 15-17 High Street, Crawley, West Sussex. Sussex Archaeological Collections 165, 193-208.

Stevens, S., 2008. Archaeological investigations at the ASDA site, Crawley, West Sussex. Sussex Archaeological Collections 146, 107-47.

Stevens, S., 2012. Archaeological investigations in the vicarage garden, Causeway, Horsham, West Sussex. Sussex Archaeological Collections 147, 123-38.

Thrift, N., 2007. Non-representational Theory: Space, politics, affect. London: Routledge.

\section{Author biography}

Ben Jervis MCIfA is lecturer in medieval archaeology at Cardiff University. He specializes in the archaeology of southern England with research interests in material culture, urban settlement and the application of theoretical approaches within medieval archaeology. He is the author of Pottery and Social Life in Medieval England: Towards a relational approach (Oxbow, 2014) and co-editor of Objects, Environment and Everyday Life in Medieval Europe (Brepols, 2016). He is assistant editor of Medieval Ceramics. 